\title{
The decorative images' seductive effect in e-learning depends on attentional inhibition
}

\author{
Federico M. González \\ Instituto de Investigaciones, Facultad de Psicología, Universidad de Buenos Aires
}

\section{Gastón Saux}

Centro de Investigaciones en Psicología y Psicopedagogía, Universidad Católica Argentina - CONICET

\section{Debora Burin}

Instituto de Investigaciones, Facultad de Psicología, Universidad de Buenos Aires - CONICET

\begin{abstract}
Two studies sought to replicate and extend the seductive effect of decorative pictures in expository text comprehension to an e-learning environment. In the first study, undergraduate students read and answered questions about two texts, with and without decorative, irrelevant images, in an e-learning course. The presence of decorative images had a small detrimental effect on comprehension. In the second study, participants read more difficult texts (low prior knowledge texts in multiple screens) and completed working memory and inhibitory ability tests. A significant interaction between comprehension and perceptual/attentional inhibitory ability was found: Participants with lower inhibitory capacity were affected by irrelevant pictures. In conclusion, evidence supported the hypothesis of a detrimental effect of irrelevant, decorative images on comprehension in e-learning, particularly for students with low attentional inhibition.
\end{abstract}

Decorative pictures are often added to expository texts with the intention of promoting engagement. However, including decorative images might act as a seductive detail and affect comprehension (Harp \& Mayer, 1998). The seductive detail effect refers to detrimental outcomes in comprehension and learning from text or multimedia when including irrelevant but motivational or emotionally appealing details. For example, Harp and Mayer (1998) found that when students read a lesson containing irrelevant illustrations about lightning formation they performed significantly worse on recall and transfer tests than students who read the text without illustrations. The seductive effect can be elicited by a text passage (Chang \& Choi, 2014; Garner, Gillingham, \& White, 1989; Lehman, Schraw, McCrudden, \& Hartley, 2007; Mayer, Griffith, Jurkowitz, \& Rothman, 2008; Rowland, Skinner, Davis-Richards, Saudargas, \& Robinson, 2008; Saux, Irrazabal, \& Burin, 2015), narration (Mayer, Heiser, \& Lonn, 2001; Yue \& Björk, 2017), images or graphical elements (Bartsch \& Cobern, 2003; Harp \& Mayer, 1998; Park, Kim, Lee, Son, \& Lee, 2005; Peshkam, Mensink, Putnam, \& Rapp, 2011; Sanchez \& Wiley, 2006), videos, or music (Moreno \& Mayer, 2000). A meta-analysis by Rey (2012) showed that the effect is reliable, small in magnitude for memory tasks and medium sized in transfer tasks. Also, the effect seems to depend on testing conditions and individual differences. Regarding testing conditions, the effect was greater with time limits and higher cognitive load in more difficult or longer texts. As for individual differences, the meta-analysis showed moderating effects of cognitive aspects (prior knowledge, working memory capacity, spatial ability) and motivational or personality dimensions such as extraversion (e.g., introverts were more affected by background music) (Rey, 2012). More recent studies also suggest that the effect depends on prior knowledge (Park, Krobach, \& Brünken, 2015; Wang \& Adesope, 2016a), attentional capacity (Chang \& Choi, 2014), motivation (Wang \& Adesope, 2016b), and strategy use, such as note-taking (Wang, Sundararajan, Adesope, \& Ardasheva, 2016).

These influences are relevant in terms of the hypotheses posited to explain the seductive detail effect. Harp and Mayer (1998) proposed three main hypotheses: drawing attention away from relevant information (distraction hypothesis), interrupting the coherent mental model construction process (disruption hypothesis), and irrelevant prior knowledge activation (schema hypothesis). They found that the best explanatory hypothesis was the activation of irrelevant schema, given that the moment when the detail was presented (early on but not at the end) led to different outcomes. Irrelevant schemas would prompt the construction of 
the text representation to be structured around that information. Nevertheless, they did not find evidence to justify either the distraction or the disruption hypothesis.

Later research, however, came to conclusions that partially contradicted those results. Although some studies found the schema activation effect (manipulating detail location) (Rowland et al., 2008; Saux et al., 2015), others did not (Lehman et al., 2007; Mayer et al., 2001). Additionally, the distraction hypothesis (Chang \& Choi, 2014; Lehman et al., 2007; Sanchez \& Wiley, 2006) and disruption hypothesis (Lehman et al., 2007; Mayer et al., 2008; Park, Moreno, Seufert, \& Brünken, 2011; Schnotz, Fries, \& Horz, 2009) gained support. In Rey's (2012) meta-analysis, evidence in favour of the different hypotheses is mixed, but the effect of the attentional component seems to be one of the most substantial. For example, Sanchez and Wiley (2006) measured individual differences in working memory capacity and studied eye fixation during reading. Both working memory capacity and eye fixations were related to the negative effect of seductive illustrations: Students with lower working memory capacity spent more time looking at the seductive detail, and more fixations on the images meant poorer performance in the comprehension task. Also, with eye tracking, Rey (2014) showed that attention to seductive details reduced comprehension. Peshkam et al. (2011) also found that eye fixations on the seductive detail were associated with less successful performance, and that instructing participants to ignore irrelevant elements helped reduce the negative impact. For Lehman et al. (2007), attention has a significant role as well, since readers focused less on the main information when seductive details were added.

The effect has been established in laboratory or classroom settings, with variables such as time limits, cognitive load, attentional and working memory demands, self-regulation, or prior knowledge as possible moderators (Rey, 2012). E-learning comprises instructional settings implemented in digital platforms, mainly for web-based or Internet learning in distance education or home-based learning, in contrast to the laboratory or classroom (Clark \& Mayer, 2016). An e-learning environment differs from controlled settings in some of the moderating factors above. In particular, participants solve tasks at home, without a teacher or researcher who could explain, guide and monitor their behaviour, therefore relying more on individual differences in technical ability, self-generated strategies, self-timing, and motivation (Broadbent \& Poon, 2015; Grice \& Hughes, 2009; Muller, Lee, \& Sharma, 2008). Related to self-regulation, another difference with laboratory or classroom-based tasks is that in these environments the computers or digital devices are configured and controlled by administrators, so that on one hand students are guided in their learning, and on the other hand they will not, or cannot, open other programs or web pages. In contrast, while learning online at home students can open multiple documents or programs, and can alternate their learning tasks with other, nontask-relevant activities. In addition, with the advances in Internet bandwidth, screen resolution, memory capacity, and computing power of digital devices, inclusion of multimedia is also common (Clark \& Mayer, 2016; Grice \& Hughes, 2009). In synthesis, e-learning environments are loaded with factors that could lead to a seductive, detrimental effect of decorative images.

Grice and Hughes (2009) tested the effects of including decorative, emotional elements in learners' affective states and comprehension outcomes in an e-learning environment. They employed music and animation (graphical and temporal aspects of typography, such as words on the screen changing colour or size). Appropriate duration and emotional positive valence evoked by music segments were tested in pilot studies. In an e-learning course, they showed a multiple-page text about learning styles and study methods in four conditions: no music and no animation (with graphical elements), text and music, text and animation, and text plus music and animation. Study condition had an impact on motivation, but did not lead to learning performance differences. In another study designed to test the effect of irrelevant but interesting multimedia on comprehension in a naturalistic e-learning setting, Muller et al. (2008) showed multimedia videos (animations, demonstrations, graphs, and narration) about radio astronomy, "gathering and analyzing electromagnetic radiation from stars" (p. 4), followed by multiple-choice and short answer comprehension questions. In one condition, a video only showed relevant multimedia, following coherence principles for textual, visual and audio information; another condition showed the same video plus interspaced segments with an astronomer talking about "exciting topics in the field" (p. 4). To manipulate previous knowledge, participants comprised 30 high school students, and 64 first year astronomy college students. Overall, comprehension results were better for college students, but did not significantly differ for both presentation 
conditions. Their discussion linked their failure to extend a laboratory finding to an authentic learning setting to similar results by Tabbers, Martens, and van Merriënboer (2004) regarding the modality and cueing multimedia effects in a more naturalistic classroom situation. Furthermore, they suggested that in an elearning situation adding interesting information helps maintain attention and motivation.

In summary, previous studies have failed to extend the seductive detail effect of multimedia to the e-learning situation (Grice \& Hughes, 2009; Muller et al., 2008). However, they have employed music, animation, and video - elements that are not easily integrated in a coherent representation of the content and have a smaller effect size than textual or pictorial elements (Rey, 2012). In addition, different small groups were assigned to different learning conditions, so that individual differences in comprehension abilities or other relevant factors might have affected the outcome.

The purpose of the present studies was to analyse whether the seductive effect of decorative pictures in expository text comprehension extended to an e-learning environment. In keeping with the seductive effect of decorative images laboratory research (Bartsch \& Cobern, 2003; Harp \& Mayer, 1998; Park et al., 2005; Peshkam et al., 2011; Sanchez \& Wiley, 2006), and as different from previous e-learning studies that employed other multimedia elements (music, video), we employed two expository texts with interspaced decorative images, in a within-subjects design. The studies followed a counterbalanced within-participants experimental approach: All participants received both experimental conditions (text with or without images), in randomised counterbalanced conditions (e.g., randomly assigned to the order of experimental conditions). First year college students completed comprehension tasks in an e-learning course specially designed for research purposes, in their home or usual place of study; relying on self-generated strategies and selfregulation and enabling them to open multiple documents or programs. Participants read two high or low prior knowledge texts, with or without decorative images, and answered questions about them. A negative impact of decorative images on comprehension was predicted, and its possible interaction with prior knowledge was also assessed.

In the second study, we tried once more to replicate and extend the decorative images' seductive effect to an e-learning situation, this time examining the attentional or distraction hypothesis (Harp \& Mayer, 1998; Lehman et al., 2007; Peshkam et al., 2011; Sanchez \& Wiley, 2006). Among all the different varieties and systems of attention, inhibition could be relevant regarding the seductive nature of the effect. Inhibitory control refers to the capacity of restricting stimuli or dominant responses, on an attentional (preventing attention to focus on irrelevant information), cognitive (deleting irrelevant information that causes extraneous load on working memory) and response level (inhibiting automatic behaviours for more adaptive ones) (Diamond, 2013). Inhibition has been associated with text comprehension in general (Arrington, Kulesz, Francis, Fletcher, \& Barnes, 2014). Working memory capacity has also been also associated with text comprehension (Arrington et al., 2014; Barreyro, Cevasco, Burin, \& Molinari Marotto, 2012) and with the seductive details effect (Sanchez \& Wiley, 2006), but as mentioned earlier its role might be attributed to the attentional component of working memory. To assess individual differences in inhibition and working memory capacity, tests were administered in an individual laboratory session. Similar to the first study, participants also completed comprehension tasks in an e-learning course. In order to maximise the seductive details effect, only low prior knowledge texts were employed. Additionally, instead of a scroll-down page, texts were shown in several pages or screens, so that the construction of a coherent representation required navigation, which rendered the task more difficult. Participants read and answered questions about two texts, presented in two versions (text only vs. text with decorative images) in counterbalanced order. The seductive effect would predict worse comprehension with decorative images, and the distraction hypothesis would predict that the detrimental effect of decorative pictures is related to low levels of attentional inhibition and working memory capacity. 


\section{Study 1}

\section{Method}

\section{Participants}

One hundred and twenty-eight first-year undergraduate students (82.5\% female, average age $=23.21$ years old, $S D=5.76)$ participated in this study for course credit. Another similar sample $(N=28)$ participated voluntarily in the pilot study for images' validation. All participants filled an informed consent form, and the project was assessed and approved by an ethics committee.

\section{Materials}

Four expository texts were employed, similar in length and argumentative structure (around 720 words in 7 nodes: main concept, two secondary concepts, details about each concept, a conclusion relating both) (Burin, Barreyro, Saux, \& Irrazábal, 2015). Given that the participants were completing an introductory cognitive psychology course, two texts presented familiar contents (language, memory: high prior knowledge condition) and the other two unfamiliar content (physics, astronomy: low prior knowledge condition) (Burin et al., 2015). In addition, each text could be presented with a hierarchical summary at the beginning with links to the different parts (text only), or a similar version with five colour decorative images (text with images). Each text was followed by 12 comprehension questions: 10 yes/no questions about literal and bridging inferences, and 2 multiple-choice questions about elaborative global inferences.

Decorative images were taken from public online sources, under the following criteria: They were found using the topics and subtopics for each text as search keywords; they could not contain any words, and they included a portrait of an author mentioned in the text. Five images per text were chosen; for example, for astronomy depictions of space, a telescope, Galileo. To validate their decorative status, they were compared with conceptual images in a pilot study (Sanchez \& Wiley, 2006). For each text, five conceptual images were designed, consisting of colour conceptual maps depicting main and subordinate concepts and their relationship, or a graph explaining a paragraph (e.g., for astronomy, how to combine information from different telescopes). Volunteer students judged the ten images' explanatory and decorative ratings, in two groups, one for each level of prior knowledge (two texts each). In a collective session, they first read each text and, with the text at hand, were shown ten images per text (mixing the five decorative and five conceptual images) in a PowerPoint presentation projected in a screen. Using a Likert scale, they rated each image according to how much it explained or clarified the content, and how much it decorated or illustrated the text. A mixed ANOVA showed an interaction of image type X rating type, $F(1,25)=12.86, p<.001, \eta 2=.53$. Ratings for explanation were significantly lower for decorative images than for conceptual images, $t(26)=$ $9.14, p<.001$. Prior knowledge did not have a significant effect, $F(1,25)=0.11$.

Texts and comprehension questions were then implemented within courses (i.e., each study condition was a course) with Moodle 2.5. Figure 1 shows text examples. They were hosted in an external institution server, to reinforce the idea that the course was part of a study and not related to their regular course grade. 
La Astronomía

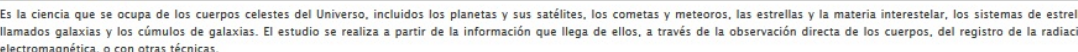
Thera, o con otras técnicas.

1.LA ASTRONOMIA

2.1PRIMEROS TELESCOPIOS

2.2TELESCOPIO OPTICO ACTUAL

RADIOASTRONOMIA

3.1 RADIOTELESCOPIOS

4.AVANCES EN ASTRONOMIA

TELESCOPIOOPTICO

Históricamente, el desarrollo de la astronomía óptica contribuyó al conocimiento del cielo. Consiste en la observación del espectro visible al ojo humano, amplificada mediante telescopios. Se denomina asi a un instrumento óptico que permite ver objetos lejanos con mucho más detalle que a simple vista, ya que amplifica la imagen a través de espejos y lentes. Un telescopio funciona por medio de uno o varios espejes del cielo.

PRIMEROS TELESCOPIOS

Ler telescopios ópticos comenzaron a desarrollarse como una extensión del ojo humano. De hecho, los primeros telescopios se elaboraron, hacia principios del 5. XVII, con lentes que se usaban para corregir

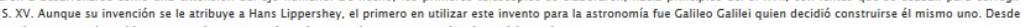

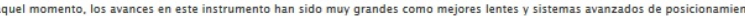

TELESCOPIO OPTICO ACTUAL

Actualmente,el telescopio más grande del mundo se llama Very Large Telescope y se encuentra en el observatorio Paranal, al norte de Chile. Consiste en cuatro telescopios ópticos reflectores que se conjugan para realizar observaciones de gran
tiempo y fuera de la atmósfera.

Figure 1. Study 1: Example of a text page (cropped)

\section{Procedure}

Participants had access to the Moodle platform through a user account created for them that was previously assigned to a reading comprehension course or condition (high or low prior domain knowledge, and type of text - with or without images - counterbalanced), received an email with the link for the course, and completed the tasks remotely, at their home or habitual place of study. Each course presented two texts, each one followed by the 12 comprehension questions, and a questionnaire about their strategies for completing the tasks (not analysed here). They were not allowed to see the questions before reading the texts. The didactic design of the e-learning sequence followed a cognitivist approach (Clark \& Mayer, 2016; Hillen \& Landis, 2014). Content was logically and linearly organised so that learners were systematically led through the material. Following information processing-based concepts and principles such as cognitive load and multimedia principles (Clark \& Mayer, 2016), as well as experimental control principles, the user interface was stripped of irrelevant content (such as extraneous text, menus, or images) so as not to distract, confuse, overload, or introduce variable confounds in the design. Figure 2 shows a sample course (e.g., testing condition). 


\section{2 .1}

Página Principal ) 16.2.1

Su progreso (2)

\section{Introducción}

Hola! Bienvenido a la investigación sobre comprensión de textos online.

Te va a llevar mas o menos media hora.

En cuanto empieces, te pedimos que sigas hasta completarlo, sin interrumpir, o mirar otras páginas en Internet. Así que elegí un momento del día que tengas una hora para concentrarte tranquilo/a.

¿No podés ahora? Marcate esta página y volvé cuando puedas.

¿Decidiste hacerlo ahora? Sigamos...

Lo primero que vas a hacer es contestar unas preguntas sobre tu experiencia de uso de Internet. Lleva unos 5 minutos.

Fl Cuestionario de Uso de Internet

\section{Texto 1}

Ahora vas a leer un texto. La tarea es leerlo atentamente, para luego responder una serie de preguntas. Se puede tomar notas o usar otros recursos, ya que no se puede consultar el texto en el momento de las preguntas.

Hace click abajo para empezar a leerlo.

뭄기

\section{Preguntas sobre el Texto 1}

A continuación, contestá unas preguntas sobre el texto que leíste.

7 Preguntas sobre Texto 1

No disponible hasta que la actividad AJ esté marcada como completa.

Texto 2

Ahora vas a leer el segundo y último texto. Nuevamente la tarea es leerlo atentamente, para luego responder una serie . $\quad$. . . . . .

Figure 2. Course example (cropped)

\section{Results and discussion}

Two participants had incomplete data, so the final sample comprised 126 students. Reliability for comprehension accuracy in each text was $\alpha$ memory $=.708 ; \alpha$ language $=.786 ; \alpha$ astronomy $=.777 ; \alpha$ physics $=.796$. Comprehension was calculated as the mean number of correct responses for each participant in each condition. Table 1 shows descriptive statistics for comprehension accuracy as a function of prior knowledge (PK; low, high) and text type (text only, image), and working memory.

Table 1

Study 1: Descriptive statistics for comprehension

\begin{tabular}{lrrrr}
\hline Condition & Mean & SD & Min & Max \\
\hline Comprehension text only, high PK & 9.61 & 1.32 & 6 & 12 \\
Comprehension text only, low PK & 9.48 & 1.49 & 6 & 12 \\
Comprehension with images, high PK & 9.29 & 1.32 & 6 & 12 \\
Comprehension with images, low PK & 9.19 & 1.61 & 5 & 12 \\
\hline
\end{tabular}

A mixed ANOVA with prior knowledge (low, high) as between- and text type (text only, image) as within subject variables, on accuracy (number correct) in comprehension answers as dependent variable, was carried out. A significant effect of text type, $F(1,123)=4.25, p=.041, \eta 2=.04$ was obtained. No other main effect or interaction reached significance (prior knowledge: $F(1,123)=0.02$, text type $\mathrm{X}$ prior knowledge: $F(1,123)=$ 
0.10 , all $p>.05$ ). Scores on comprehension were significantly lower for the texts with decorative images (with image $M=9.24, S D=1.47$ : no image $M=9.54, S D=1.41$ ).

Overall, a detrimental effect of decorative images was found, but it was very small in magnitude $(\eta 2=.04)$. On one hand, this could be due to methodological issues of this study. For example, the comprehension questions, in true/false format, might have been easy (averaging around 9/12), thus creating ceiling effects. In addition, the texts were shown in a single page, where participants advanced with scrolling. Although Sanchez and Wiley (2009) found that scrolling negatively affected comprehension (measured with short essays), other research has found that texts are more difficult when the reader must integrate content from multiple pages through navigation (e.g., Amadieu \& Salmerón, 2014). Thus, in this case, it is possible that the scrolling format contributed to the lack of difficulty. On the other hand, the effect could be small due to the ecological conditions of testing, where numerous other factors could explain comprehension such as Internet skills, offline verbal ability, strategies and metacognitive aspects, and motivation and self-regulation (Hahnel, Goldhammer, Naumann, \& Kröhne, 2016). Thus, the effect might exist, but might be small in magnitude in comparison with other influences on task performance.

\section{Study 2}

A second study was carried out, in the first place, to try to replicate the seductive effect of decorative pictures on text comprehension in e-learning, due to the small effect size found in Study 1, and to analyse the possible moderating effects of attention and working memory.

In term of materials, the effect is expected to be stronger with longer, more difficult texts. For this reason, only the low prior knowledge texts were used, adding length (in both cases, examples were incorporated to make explanations clearer, as well as irrelevant information such as historical details) and navigation. For the dependent variable, all questions were changed to a multiple-choice modality (four possible answers instead of true/false) and were reformulated to require bridging and elaborative inferences, rather than literal recall of the content.

\section{Method}

\section{Participants}

Sixty-five undergraduate psychology students $(84 \%$ female, average age $=22.32$ years, $S D=4.31)$ volunteered to participate in the study, in exchange for course credit. Four cases were excluded: three of them did not complete either the online comprehension or the inhibition/working memory task, and the other one reported daltonism (inhibition tasks included red and blue figures). As in the previous study, all participants filled an informed consent form.

\section{Materials}

The low prior knowledge texts (astronomy, physics) used in Study 1 were adapted and extended to 8-node hypertexts with an average length of 1600 words. The additional information was both relevant (e.g., explanation for main concepts) and irrelevant (e.g., more details about historical aspects). Each text was followed by ten multiple-choice comprehension questions. The same five decorative images described in Study 1 were used, shown in five different pages or nodes. Figure 3 shows an example of a text page. 


\section{TP Lectura online 16.22.2}

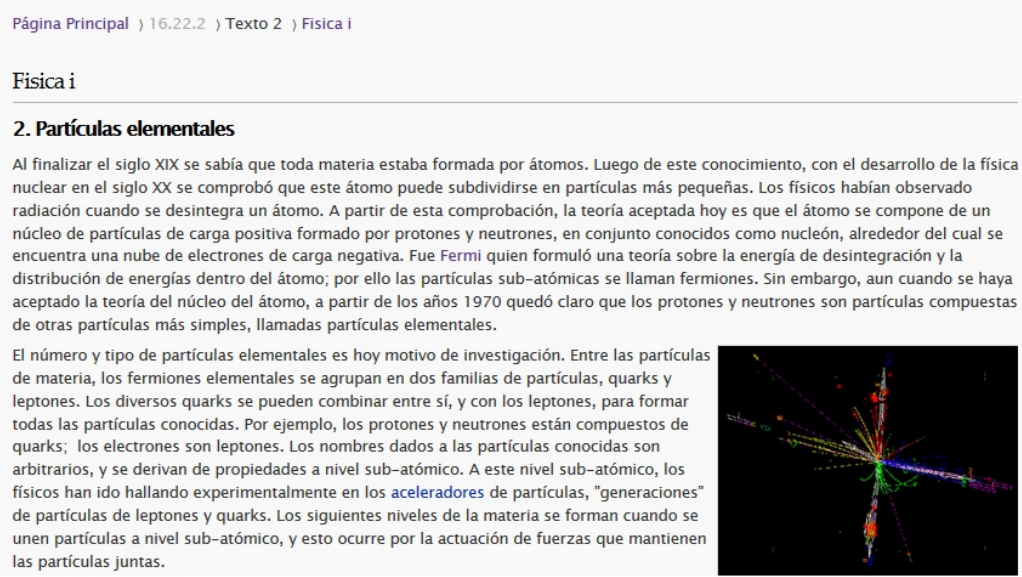

Al finalizar el siglo XIX se sabía que toda materia estaba formada por átomos. Luego de este conocimiento, con el desarrollo de la física nuclear en el siglo XX se comprobó que este átomo puede subdividirse en partículas más pequeñas. Los físicos habían observado encuentra una nube de electrones de carga negativa. Fue Fermi quien formuló una teoría sobre la energía de desintegración y la distribución de energías dentro del átomo; por ello las partículas sub-atómicas se llaman fermiones. Sin embargo, aun cuando se haya décos de otras partículas más simples, llamadas partículas elementales. las partículas juntas.

Figure 3. Study 2: Example of a text page (cropped)

Attentional inhibition task: Visual search from the computerised cognitive self-regulation battery (tareas de autorregulación cognitiva [TAC]; Introzzi, Canet Juric, Montes, López, \& Mascarello, 2015) was employed. Based on the Treisman and Gelade (1980) paradigm, participants had to indicate if there was a target (blue square) or not in an array of distractors (red squares and blue circles) varying in quantity. The perceptual inhibition index was calculated as the performance difference between the 32 and 16 distractor sets: higher scores evidence less efficient interference control on a perceptual level.

Cognitive inhibition task: Updating task from the computerised cognitive self-regulation battery (Introzzi et al., 2015) was employed. Based on Oberauer (2001), abstract red and blue figures were jointly presented for two seconds, after which a black figure and a colour signal (red or blue) appeared; the participant had to answer if the black figure appeared in that signal colour. The black figure could have been in that set (relevant), or on the other colour set (intruder), or it could be a novel figure. The cognitive inhibition index was calculated as the difference in correct answers between intruder and novel items: higher scores indicate lower cognitive inhibition capacity.

Response inhibition task: Stop signal task from the computerised cognitive self-regulation battery (Introzzi et al., 2015) was employed. An arrow was presented on the centre of the screen, and participants were asked to indicate as fast as possible its pointing direction with the right or left key. Then, in a second part, participants had to keep responding rapidly, except when a randomly presented noise sounded, in which case they had to prevent their responding. The response inhibition index was calculated as the percentage of correctly prevented responses.

Working memory task: Letter-number sequencing subtest from the Wechsler (1997) adult intelligence scale was employed. A series of numbers and letters sets were presented one by one. Set sizes varied in length (three to eight). After each set, participants had to recall first the numbers in ascending order, then the letters in alphabetical order. The working memory capacity index was the total of correct answers, following a discontinuation rule.

\section{Procedure}

Participants read and answered questions about two texts in a similar way as in Study 1. In a previous face-toface individual session lasting approximately 40 minutes, participants completed the working memory capacity and perceptual, cognitive, and response inhibition tasks. 


\section{Results and discussion}

Three participants had incomplete data, so the final sample comprised 58 participants. Table 2 shows descriptive statistics for comprehension in both conditions (with and without images) and working memory and inhibition measures. The variables distribution was normal, and all Kolmogorov-Smirnov tests $p>.05$. Reliability of the comprehension measure was $\alpha=.59$.

Table 2

Study 2: Descriptive statistics for comprehension, working memory and inhibition

\begin{tabular}{lcccc}
\hline Measures & Mean & SD & Min & Max \\
\hline Comprehension (text only) & 5.37 & 1.98 & 2 & 10 \\
Comprehension (with images) & 5.36 & 1.61 & 1 & 9 \\
Working memory & 11.72 & 3.38 & 6 & 19 \\
Visual search & 4.89 & 5.87 & -6.67 & 16.67 \\
Updating & -27.83 & 70.50 & -167 & 150 \\
Stop-signal & 57.66 & 7.13 & 44 & 72 \\
\hline
\end{tabular}

A mixed ANOVA was carried out with text type (text only, image) as within subject variable and working memory and perceptual, cognitive, and response inhibition capacities as covariates, on accuracy in comprehension as dependent variable. There was no significant effect of text type, $F(1,53)=0.02, p>.05$. However, a significant interaction between text type and visual search accuracy (attentional inhibitory control) was found, $F(1,53)=9.18, p<.01, \eta 2=.15$, in the sense that comprehension varied negative and linearly with visual search (VS) scores (VS text only $B=-0.14, S E=0.04$; VS image $B=-0.01, S E=0.03$ ). No other interactions reached significance: cognitive inhibitory control, $F(1,53)=0.05, p>.05$; response inhibitory control, $F(1,53=0.06, p>.05$; working memory, $F(1,53)=0,08, p>.05)$ (although an effect of working memory capacity over general comprehension was found: $F(1,53)=4,63, p<.05)$. To visualise the interaction, the visual search was dichotomised at the median creating two groups (low and high attentional inhibition capacity). Figure 4 shows the mean accuracy for each group and condition.

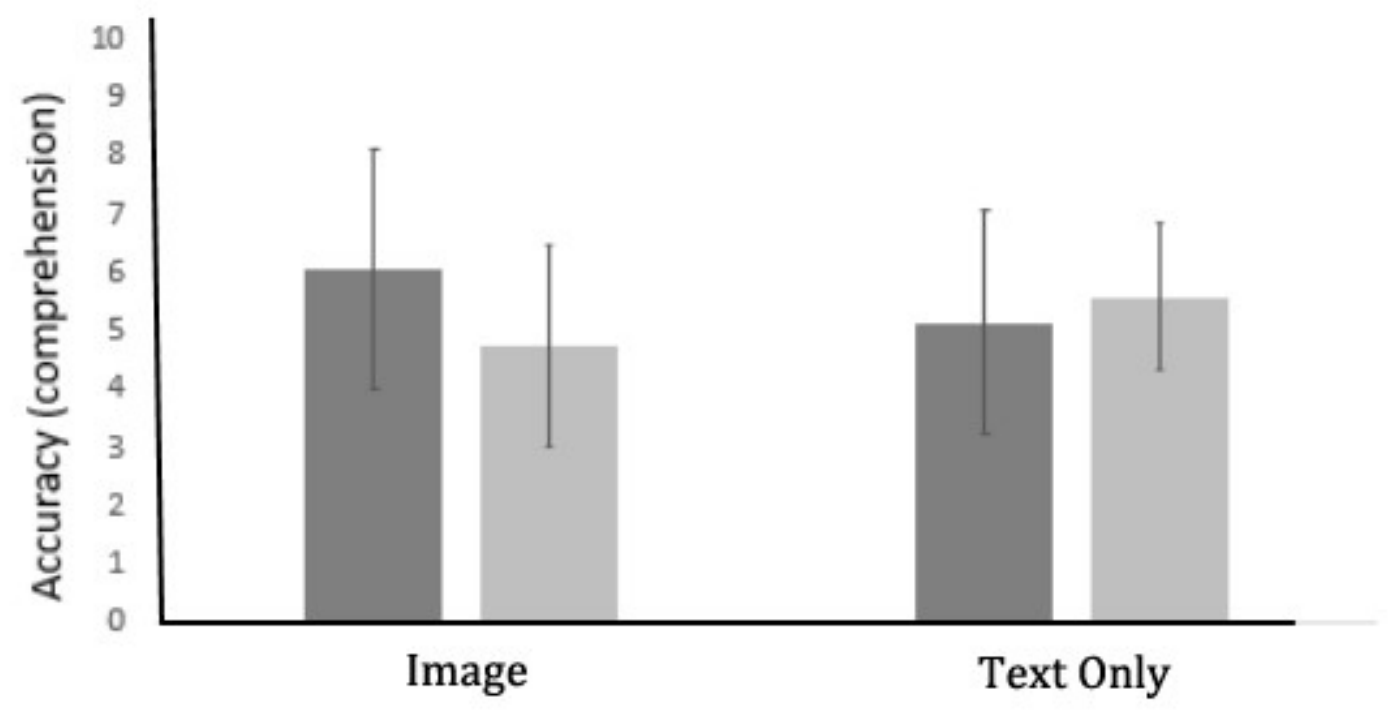

\section{- High attentional inhibition $\quad$ Low attentional inhibition}

Figure 4. Study 2: Mean accuracy (comprehension) for attentional inhibition capacity groups in the image and text only conditions 
These results show a negative impact of decorative images in comprehension for students with lower attentional inhibitory control capacity. This would support the attention distraction hypothesis (Chang \& Choi, 2014; Lehman et al., 2007; Sanchez \& Wiley, 2006), suggesting that seductive details draw the focus of attention from relevant information, promoting a superficial or incorrect processing. The fact that the other inhibition measures were not significant in relation to the effect highlights the perceptual nature of the disruption produced by decorative images in the e-learning environment. In addition, the effect does not seem to be related to working memory overload.

\section{General discussion}

The present studies sought to analyse whether the seductive effect of decorative pictures in expository text comprehension found in controlled settings extended to an e-learning environment. The effect was not found in previous studies (Grice \& Hughes, 2009; Muller et al., 2008) employing multimedia elements (music, video, animation) that showed smaller effect sizes than textual or pictorial elements (Rey, 2012), and in between-subjects designs with small groups. In contrast, the present research had participants read two expository texts with interspaced decorative images (Bartsch \& Cobern, 2003; Harp \& Mayer, 1998; Park et al., 2005; Peshkam et al., 2011; Sanchez \& Wiley, 2006), in a within-subjects design. They completed the task in an e-learning course, specially designed for research purposes, in their home or usual place of study.

The first study tried to replicate and extend the decorative images' seductive effect. Participants read two high or low prior knowledge texts, with or without decorative images, and answered literal and inferential questions about them, online. A negative impact of decorative images on comprehension was found, but was small in magnitude. Given that previous knowledge did not have a significant effect, the pattern of results of this study might be attributed to methodological issues, such as a ceiling effect in comprehension because the questions were too easy (given that some of them tapped literal answers), or a combination of showing the text in a single page with easy questions. The second study increased the difficulty of the task by employing only low previous knowledge texts, shown in several pages or screens, so that the construction of a coherent representation required navigation, and changing the comprehension questions to require elaborative inferences. In this second study, there was no significant overall main effect of decorative pictures on comprehension, but there was an interaction between images and subject factors, in the sense that low attentional inhibition capacity participants had lower comprehension with decorative images. Therefore, the hypothesis of a general disruptive effect of decorative pictures on comprehension in e-learning seems to be supported. It would be small in magnitude, perhaps because in e-learning at home numerous other factors could explain comprehension, such as Internet skills, offline verbal ability (Hahnel et al., 2016), strategies and metacognitive aspects, and motivation and self-regulation (Afflerbach \& Cho, 2009; Broadbent \& Poon, 2015). Thus, the effect might be dependent on other task conditions and subject factors, as in the findings in controlled settings (e.g., Rey, 2012). Our findings also contrast with the suggestion that including decorative pictures could benefit task performance by enhancing interest and motivation (Park et al., 2011; Schnotz et al., 2009), given that the effect of the decorative pictures was, if anything, negative.

One of the main relevant factors seems to be attentional capacity and control. There was one group of participants for whom decorative images impaired performance in Study 2 - those with low perceptual inhibition. Students who had lower capacity to prevent attention focusing on irrelevant information had lower comprehension when the texts were presented with decorative images. This result is in line with the attentional or distraction hypothesis (Harp \& Mayer, 1998; Lehman et al., 2007; Peshkam et al., 2011; Sanchez \& Wiley, 2006), which posits that seductive illustrations have detrimental effects on comprehension and learning because they draw students' attention to irrelevant information, which in turn can promote superficial processing, detract resources from required learning processes, or activate incorrect schemas. Our result in a more ecological setting complements laboratory findings measuring eye fixation (Peshkam et al., 2011; Rey, 2014; Sanchez \& Wiley, 2006).

One possible limitation was the use of a verbal working memory capacity measure, but not a visual one, as the latter might be involved in the processing of the images. Another limiting factor in this set of studies is the 
didactic design, which maximises the internal validity of the study; other studies could examine how if and how the phenomena described in these studies are present in other didactic designs (e.g., constructivist approaches) and contexts.

\section{Conclusion, implications, and future research}

We found evidence for a detrimental effect on comprehension in e-learning, particularly for students with low attentional inhibition. Thus, we replicated and extended the seductive detail effect of decorative images in text comprehension in a more ecological e-learning situation, where multiple influences occur and self-regulation becomes especially relevant. In a broader sense, replication (Open Science Collaboration, 2015) and validation of experimental effects in applied settings (Henrich, Heine, \& Norenzayan, 2010) have recently become concerns of psychological research; this study contributes in these directions.

Our results might be relevant given that online learning is one of the fastest growing tendencies in education, particularly at higher level education. Within this e-learning expansion, interface design should consider the possible detrimental effects of decorative pictures; graphic designers should also work along thematic experts to create appealing images with instructional value.

Future research could include more factors (emotional valence, image size and characteristics) and larger samples to test multiple causal models. Additionally, as nowadays many people learn content through a second language and considering the effect it has on loading working memory, further research could investigate the impact of images in this particular case.

\section{Acknowledgements}

This work was supported by Secretaria de Ciencia y Tecnica, Universidad de Buenos Aires UBACYT 20020150100024BA and Agencia Nacional de Promocion Cientifica y Tecnologica PICT-2015-2706 grants.

\section{References}

Amadieu, F., \& Salmerón, L. (2014). Concept maps for comprehension and navigation of hypertexts. In R. Hanewald \& D. Ifenthaler (Eds.), Digital knowledge maps in education (pp. 41-59). New York, NY: Springer.

Afflerbach, P. \& Cho, B. (2009). Determining and describing reading strategies. In H. S. Waters \& W. Schneider (Eds.), Metacognition, strategy use, and instruction (pp. 201-255). New York, NY: Guilford Press.

Arrington, C. N., Kulesz, P., Francis, D., Fletcher, J., \& Barnes, M. (2014). The contribution of attentional control and working memory to reading comprehension and decoding. Scientific Studies of Reading. 18(5), 325-346- http://doi.org/10.1080/10888438.2014.902461

Barreyro, J. P., Cevasco, J., Burin, D. I., \& Molinari Marotto, C. (2012). Working memory capacity and individual differences in the making of reinstatement and elaborative inferences. Spanish Journal of Psychology, 15(2), 471-479. https://doi.org/10.5209/rev_SJOP.2012.v15.n2.38857

Bartsch, R. A., \& Cobern, K. M. (2003). Effectiveness of PowerPoint presentations in lectures. Computers and Education, 41(1), 77-86. https://doi.org/10.1016/S0360-1315(03)00027-7

Broadbent, J. \& Poon, W.L. (2015). Self-regulated learning strategies \& academic achievement in online higher education learning environments: A systematic review. Internet and Higher Education, 27, 1-13. https://doi.org/10.1016/j.iheduc.2015.04.007

Burin, D., Barreyro, J., Saux, G., \& Irrazábal, N. (2015). Navigation and comprehension of digital expository texts: Hypertext structure, previous domain knowledge, and working memory capacity. Electronic Journal of Research in Educational Psychology, 13(3), 529-550. https://doi.org/10.14204/ejrep.37.14136

Chang, Y., \& Choi, S. (2014). Effects of seductive details evidenced by gaze duration. Neurobiology of Learning and Memory, 109, 131-138. https://doi.org/10.1016/j.nlm.2014.01.005 
Clark, R. C. \& Mayer, R. (2016). E-learning and the science of instruction: Proven guidelines for consumers and designers of multimedia learning. Hoboken, NJ: Wiley.

Diamond, A. (2013). Executive functions. Annual Review of Psychology, 64, 135-168. https://doi.org/10.1146/annurev-psych-113011-143750

Garner, R., Gillingham, M. G., \& White, C. S. (1989). Effects of ‘seductive details' on macroprocessing and microprocessing in adults and children. Cognition and Instruction, 6(1), 41-57. https://doi.org/10.1207/s1532690xci0601_2

Grice, S. \& Hughes, J. (2009). Can music and animation improve the flow and attainment in online learning? Journal of Educational Multimedia and Hypermedia, 18(4), 385-403. Retrieved from https://www.learntechlib.org/p/30275/

Hahnel, C., Goldhammer, F., Naumann, J., \& Kröhne, U. (2016). Effects of linear reading, basic computer skills, evaluating online information, and navigation on reading digital text. Computers in Human Behavior, 55, 486-500. https://doi.org/10.1016/j.chb.2015.09.042

Harp, S. F., \& Mayer, R. E. (1998). How seductive details do their damage: A theory of cognitive interest in science learning. Journal of Educational Psychology, 90(3), 414-434. https://doi.org/10.1037/00220663.90.3.414

Henrich, J., Heine, S. J., \& Norenzayan, A. (2010). The weirdest people in the world? Behavioral and Brain Sciences, 33, 1-75. https://doi.org/10.1017/S0140525X0999152X

Hillen, S., \& Landis, M. (2014) Two perspectives on e-learning design: A sypnosis of a U.S. and European analysis. International Review of Research in Open and Distance Learning, 15(4), 199-225. https://doi.org/10.19173/irrodl.v15i4.1783

Introzzi, I. M., Canet Juric, L., Montes, S., López, S., \& Mascarello, G. (2015). Procesos inhibitorios y flexibilidad cognitiva: Evidencia a favor de la teoría de la inercia atencional [Inhibitory processes and cognitive flexibility: Evidence for the theory of attentional inertia]. International Journal of Psychological Research, 8(2), 61-75. Retrieved from http://www.redalyc.org/pdf/2990/299040283006.pdf

Lehman, S., Schraw, G., McCrudden, M. T., \& Hartley, K. (2007). Processing and recall of seductive details in scientific text. Contemporary Educational Psychology, 32(4), 569-587. https://doi.org/10.1016/j.cedpsych.2006.07.002

Mayer, R. E., Griffith, E., Jurkowitz, I. T. N., \& Rothman, D. (2008). Increased interestingness of extraneous details in a multimedia science presentation leads to decreased learning. Journal of Experimental Psychology: Applied, 14(4), 329-339. https://doi.org/10.1037/a0013835

Mayer, R. E., Heiser, J., \& Lonn, S. (2001). Cognitive constraints on multimedia learning: When presenting more material results in less understanding. Journal of Educational Psychology, 93(1), 187-198. https://doi.org/10.1037/0022-0663.93.1.187

Moreno, R., \& Mayer, R. E. (2000). A coherence effect in multimedia learning: The case for minimizing irrelevant sounds in the design of multimedia messages. Journal of Educational Psychology, 92(1), 117125. https://doi.org/10.1037//0022-0663.92.1.117

Muller, D. A., Lee, K. J., \& Sharma, M. D. (2008). Coherence or interest: Which is most important in online multimedia learning? Australasian Journal of Educational Technology, 24(2), 211-221. https://doi.org/10.14742/ajet.1223

Oberauer, K. (2001). Removing irrelevant information from working memory: A cognitive aging study with the modified Sternberg task. Journal of Experimental Psychology, 27(4), 948-957. https://doi.org/10.1037/0278-7393.27.4.948

Open Science Collaboration. (2015). Estimating the reproducibility of psychological science. Science, 349, 943-950. https://doi.org/10.1126/science.aac4716

Park, B., Krobach, A., \& Brünken, R. (2015). Do learner characteristics moderate the seductive-details-effect? A cognitive-load-study using eye-tracking. Journal of Educational Technology \& Society, 18(4), 24-36. Retrieved from https://www.j-ets.net/ETS/journals/18_4/3.pdf

Park, B., Moreno, R., Seufert, T., \& Brünken, R. (2011). Does cognitive load moderate the seductive details effect? A multimedia study. Computers in Human Behavior, 27(1), 5-10. https://doi.org/10.1016/j.chb.2010.05.006

Park, S., Kim, M., Lee, Y., Son, C., \& Lee, M. (2005). The effects of visual illustrations on learners' achievement and interest in personal digital assistant (PDA) based learning. Journal of Educational Computing Research, 33(2), 173-188. https://doi.org/10.2190/ELEY-NPQN-0WVM-FW0G 
Peshkam, A., Mensink, M. C., Putnam, A. L., \& Rapp, D. N. (2011). Warning readers to avoid irrelevant information: When being vague might be valuable. Contemporary Educational Psychology, 36(3), 219231. https://doi.org/10.1016/j.cedpsych.2010.10.006

Rey, G. D. (2012). A review of research and a meta-analysis of the seductive detail effect. Educational Research Review, 7(3), 216-237. https://doi.org/10.1016/j.edurev.2012.05.003

Rey, G. D. (2014). Seductive details and attention distraction. an eye tracker experiment. Computers in Human Behavior, 32, 133-144. https://doi.org/10.1016/j.chb.2013.11.017

Rowland, E., Skinner, C. H., Davis-Richards, K., Saudargas, R., \& Robinson, D. H. (2008). An investigation of placement and type of seductive details: The primacy effect of seductive details on text recall. Research in the Schools, 15(2), 80-90.

Sanchez, C., \& Wiley, J. (2006). An examination of the seductive details effect in terms of working memory capacity. Memory \& Cognition, 34(2), 344-355. https://doi.org/10.3758/BF03193412

Saux, G., Irrazabal, N., \& Burin, D. (2015). Uso estratégico de representaciones pictóricas en un texto de ciencias con un detalle seductor en lectores con bajo conocimiento previo [Strategic use of pictorial representations in a Science text with a biographical seductive detail in low prior knowledge readers]. Revista Signos: Estudios de Lingüística, 48(89), 401-424. https://doi.org/10.4067/S071809342015000300006

Schnotz, W., Fries, S., \& Horz, H. (2009). Motivational aspects of cognitive load theory. In M. Wosnitza, S. A. Karabenick, A. Efklides, \& P. Nenniger (Eds.), Contemporary motivation research: From global to local perspectives (pp. 69-96). Göttingen: Hogrefe \& Huber.

Tabbers, H. K., Martens, R. L. \& van Merriënboer, J. J. G. (2004). Multimedia instruction and cognitive load theory: Effects of modality and cueing. British Journal of Educational Psychology, 74(1), 71-81. https://doi.org/10.1348/000709904322848824

Treisman, A.M., \& Gelade, G. (1980). A feature integration theory of attention. Cognitive Psychology, 12(1), 97-136. https://doi.org/10.1016/0010-0285(80)90005-5

Wang, Z., \& Adesope, O. (2016a). Does learners’ prior knowledge moderate the detrimental effects of seductive details in reading from text? A 2 by 3 study. International Journal of Instruction, 9(2), 3650.Retrieved from http://www.e-iji.net/dosyalar/iji_2016_2_3.pdf

Wang, Z., \& Adesope, O. (2016b). Exploring the effects of seductive detail with the 4-phasemodel of interest. Learning and Motivation, 55, 65-77. https://doi.org/10.1016/j.lmot.2016.06.003

Wang, Z., Sundararajan, N., Adesope, O., \& Ardasheva, Y. (2016). Moderating the seductive detail effect in multimedia learning with note-taking. British Journal of Educational Technology, 48(6), 1380-1389. https://doi.org/10.1111/bjet.12476

Wechsler, D. (1997). WAIS - III Manual. San Antonio, TX: The Psychological Corporation.

Yue, C., \& Björk, E. L. (2017) Using selective redundancy to eliminate the seductive details effect. Applied Cognitive Psychology, 31(5), 565-571. https://doi.org/10.1002/acp.3348

Corresponding author: Federico M. González, fmgonzalez@psi.uba.ar

Please cite as: González, F. M., Saux, G., \& Burin, D. (2019). The decorative images’ seductive effect in elearning depends on attentional inhibition. Australasian Journal of Educational Technology, 35(3), 166178. https://doi.org/10.14742/ajet.4577 